\title{
Experimental research and CFD analysis of flow parameters in a SCR system for the original part and WALKER's replacement
}

The article presents the results of experimental research and their comparison with CFD simulations for the original selective catalytic reduction system and WALKER replacement. The research was performed to develop the WALKER universal mixer. The SCR prototype without mixer and with the proposed mixer were tested and compared with the original VW part. The next step was reverse engineering, which consisted in scanning the tested parts with a laser and processing their point cloud in Leios 2 program. Reverse engineering has allowed the reconstruction of $3 D$ geometry of the tested parts in the Catia v5 program and then preparation their models for computational fluid dynamics. Numerical simulations were carried out in the Ansys Fluent program, thanks to which several quantities were determined e.g. uniformity index of gas flow through the monolith and coefficient of variation as a measure of mixing degree, which have a significant impact on the design of the mixer and the SCR system.

Key words: selective catalytic reduction, computational fluid dynamic, static mixer, uniformity index, coefficient of variation

\section{Introduction}

At the present day, a future without diesel engines does not seem real for light, heavy duty vehicles and off-road machinery. For such a large number of applications, there are no alternatives when it comes to environmental and economic objectives. Acceptance of this trend by society and customers, causes tightening of euro standards (Table 1), mainly by reducing $\mathrm{NO}_{\mathrm{x}}, \mathrm{PM}$ and use of other test methods but also entering a limit for $\mathrm{CO}_{2}$ emissions $(95 \mathrm{~g} / \mathrm{km}$ until 2021) [6]. Therefore, the diesel engines are constantly improving as well as the exhaust system in terms of fuel consumption and reducing of harmful exhaust gas components.

Table 1. Euro 5 and 6 standards for a diesel engine - new types approval for $\mathrm{M}$ vehicle category $[6,10]$

\begin{tabular}{|c|c|c|c|}
\hline $\begin{array}{c}\text { Euro } \\
\text { standard }\end{array}$ & $\begin{array}{c}\text { Date } \\
\text { from }\end{array}$ & $\begin{array}{c}\text { Test } \\
\text { cycle }\end{array}$ & $\begin{array}{c}\mathrm{NO}_{\mathrm{x}} \\
{[\mathrm{g} / \mathrm{km}]}\end{array}$ \\
\hline $5 \mathrm{a}$ & 9.09 & NEDC & 0.18 \\
\hline $5 \mathrm{~b}$ & 9.11 & NEDC & $0.18 * *$ \\
\hline $6 \mathrm{~b}$ & 9.14 & NEDC & 0.08 \\
\hline $6 \mathrm{c}$ & $-*$ & WLTP & 0.08 \\
\hline 6d-temp & 9.17 & WLTP + RDE & $\mathrm{CF}=2.1:$ WLTP $0.08 ; \mathrm{RDE} 0.168$ \\
\hline 6d & 1.20 & WLTP + RDE & $\mathrm{CF}=1.5:$ WLTP $0.08 ; \mathrm{RDE} 0.120$ \\
\hline$*$ For new vehicles -1 st registration from 09.2018 \\
**Changed PM from 5.0 to 4.5 [mg/km] and added PN $6.0 * \mathrm{~m} 11[\# / \mathrm{km}]$ \\
\hline
\end{tabular}

From Euro 5a to $6 \mathrm{~b}$ standard, diesel cars had significant divergence between the results of the NEDC (New European Driving Cycle) laboratory test and reality. For this reason, the Worldwide Harmonized Light Vehicle Test Procedure (WLTP) has been introduced which refers to the actual conditions in which drivers travel. The complement of this laboratory test is the Real Driving Emission (RDE) which is road test using Portable Emission Measurement System (PEMS). For the automotive industry to be allowed sufficient lead-time to adapt its strategies for new test cycle, a Conformity Factor (CF) has been introduced which is the maximum ratio between the emission limit in the laboratory test and measured in the road test $[6,10]$.

To fulfill this rising challenge, there are two main technologies to reduce the $\mathrm{NO}_{\mathrm{x}}$ from diesel engine gases [1]
The first of them is the Lean $\mathrm{NO}_{\mathrm{x}}$ Traps (LNT) or $\mathrm{NO}_{\mathrm{x}}$ Storage Catalyst (NSC). Reactors store $\mathrm{NO}_{\mathrm{x}}$ under lean condition, then under the fuel-rich engine condition, the $\mathrm{NO}_{x}$ are released and reduced from base of barium carbonate $\left(\mathrm{BaCO}_{3}\right)$. LNT technologies are insufficient to provide desired $\mathrm{NO}_{\mathrm{x}}$ emission reduction, especially for engines with larger capacities [3, 11].

The second most used technology for reduction of nitrogen oxides over $90 \%$ from exhaust gases of diesel engine is the SCR (Selective Catalytic Reduction) system (Fig. 1). This method uses an injector to inject the urea-water solution (UWS) also known as AdBlue or Diesel Exhaust Fluid (DEF) into the hot exhaust upstream of the SCR monolith. Due to limited amount of space, more and more often meets ones called the SDPF (SCR - Catalyzed Diesel Particulate Filter), which means the SCR coated onto a DPF [11, 12].

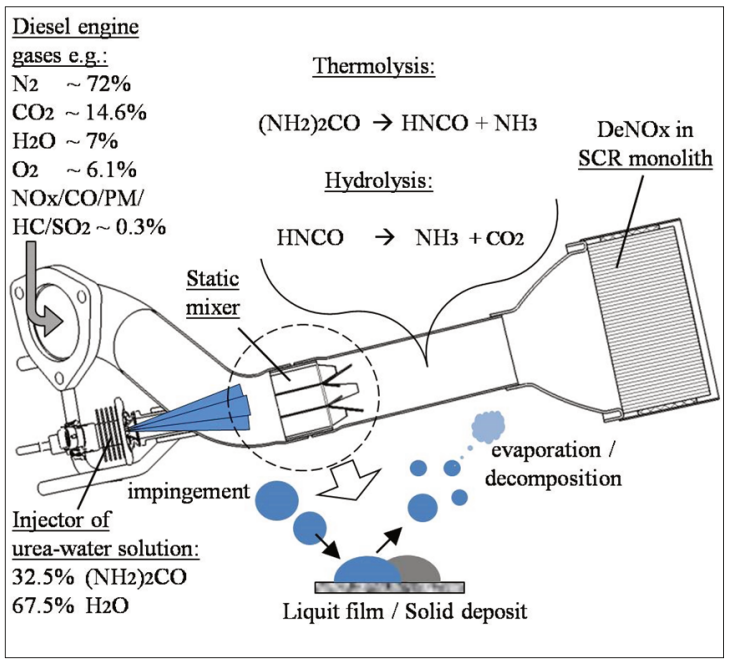

Fig. 1. Sketch showing the physical and chemical processes in SCR system

The UWS are heated up by exhaust gas and decomposes (thermolysis) to ammonia $\left(\mathrm{NH}_{3}\right)$ and isocyanic acid (HNCO), which in turn reacts (hydrolysis) with water vapour $\left(\mathrm{H}_{2} \mathrm{O}\right)$ to ammonia and carbon dioxide $\left(\mathrm{CO}_{2}\right)$ [1, 15]. 
At the low exhaust gas temperature (before light-off) on the supercooled surfaces, tip of injector, mixer or inlet surface of monolith a liquid layer (wall film) of UWS crystallizes after evaporation of water, forming deposit (e.g. biuret, cyanuric acid). This may lead to reducing catalyst activity or increasing engine backpressure [3,9].

The most important $\mathrm{NO}_{\mathrm{x}}$ reactions are called standard, fast and slow and their priority depends on $\mathrm{NO}_{2} / \mathrm{NO}_{\mathrm{x}}$ ratio (increasing DeNOx up to 0.5 ratio). They mainly turn into to harmless nitrogen $\left(\mathrm{N}_{2}\right)$ and water [7]. The required amount of UWS dosing for complete conversion of $\mathrm{NO}_{\mathrm{x}}$ can be determined by means of the feed ratio $\alpha$ defined as:

$$
\alpha=\frac{\mathrm{NH}_{3, \text { in }}}{\mathrm{NO}_{\mathrm{x}, \mathrm{in}}}
$$

where: $\mathrm{NH}_{3 \text {,in }}$ - amount of $\mathrm{NH}_{3}$ molecules from the urea, $\mathrm{NO}_{\mathrm{x}, \mathrm{in}}$ - amount of NOx molecules in exhaust gases.

The stoichiometric feed ratio of $\alpha=1$ is theoretically required for complete conversion of $\mathrm{NO}_{\mathrm{x}}[11,15]$.

Good SCR systems combine high $\mathrm{NO}_{\mathrm{x}}$ conversion with low ammonia slip, which is undesired emission. To meet these requirements, there are three main types of SCR reactors, which differ in some properties. Vanadia SCR catalysts contain $\mathrm{V}_{2} \mathrm{O}_{5}(1-3 \%)$ as the active component, typically impregnated on an anatase $\mathrm{TiO}_{2}$ support together with $\mathrm{WO}_{3}$ to stabilize the vanadia and increase thermal durability. $\mathrm{V}_{2} \mathrm{O}_{5}-\mathrm{WO}_{3} / \mathrm{TiO}_{2}$ characterizes high conversion in medium range temperatures $\left(250-550^{\circ} \mathrm{C}\right)$. Cu-zeolite SCR catalysts $(\mathrm{Cu}-\mathrm{ZSM}-5)$, exhibit higher $\mathrm{NO}_{\mathrm{x}}$ conversion at low temperatures $\left(200-650^{\circ} \mathrm{C}\right)$, while Fe-zeolite SCR catalysts (Fe-ZSM-5), show higher $\mathrm{NO}_{\mathrm{x}}$ reduction at high temperatures $\left(350-700^{\circ} \mathrm{C}\right)$. Furthermore, $\mathrm{Cu}-\mathrm{ZSM}-5$ catalysts have the greatest possibility of $\mathrm{NH}_{3}$ storage $[7,11]$.

The best way to achieve the optimal $\mathrm{NO}_{\mathrm{x}}$ aftertreatment system is presented in Fig. 2. The most important part of the development process flow is the initial engineering. It consists of the definition of goals (emission regulation, type of UWS, level of $\mathrm{NO}_{\mathrm{x}}$ reduction and backpressure), quantifying inputs (engine emission data, allowable packaging space and work cycle) and development of the initial design. The next step is simulation that allows quickly evaluate designs without the additional costs associated with building hardware and running tests. After this step, hardware testing should be performed to evaluate $\mathrm{NO}_{\mathrm{x}}$ reduction and deposit formation. Following a defined process will help to complete $\mathrm{NO}_{x}$ aftertreatment system, meeting the emission certification and saving time and money [4].

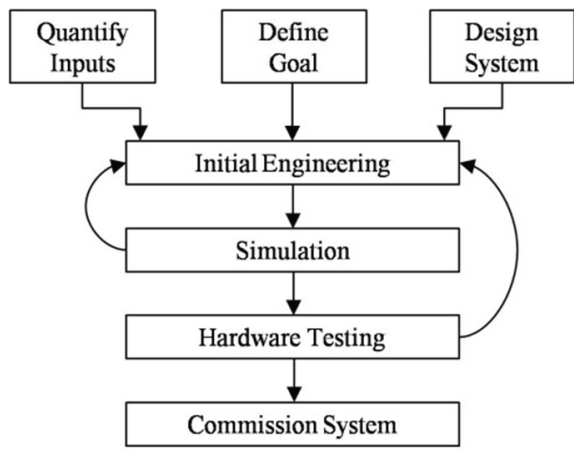

Fig. 2. SCR development process flow
Focusing attention on the process of designing a mixer (Fig. 3), many parameters affect the performance of a mixer such as tube diameter, injector types, injector mounting angle, mass flow rate, temperature, mixing length etc. As mentioned in the study of Zheng et al. [15], it is unrealistic to expect a mixer to perform well in all applications without carefully tuning it to a given exhaust environment. Therefore, development cycle starts with new 3D concept through CFD then prototypes and laboratory tests are initiated to confirm analytical results. Finally, deposit checking and durability are studied and eventually changes are introduced [15].

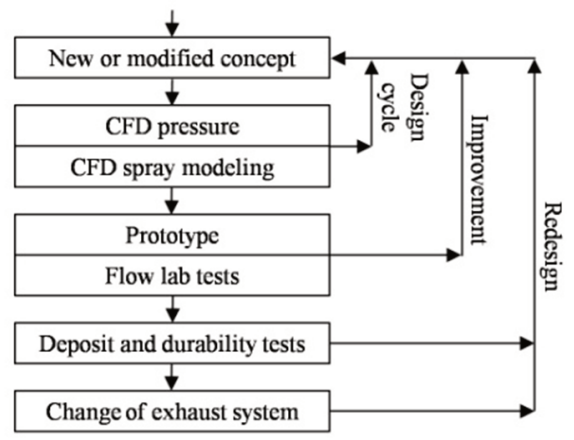

Fig. 3. Mixer development process flow

\section{Experimental}

The aim of the research within this study was to compare the WALKER SCR replacement prototype for aftermarket (AM) with the original SCR part (for VW Passat 2.0 BlueTDi 103kW, 2010-2014, fulfilling Euro 6, common rail) [2]. The SCR system consisted of two SCR reactors, however in this paper we focused on the first of them (front part with an injector and a mixer).

Several experimental studies and all numerical simulations have been performed according to cases, as presented in Table 2. The SCR system was examined without mixer and with proposed WALKER mixer. What's more, they were compared with the original VW part and mixer.

Table 2. Investigated cases

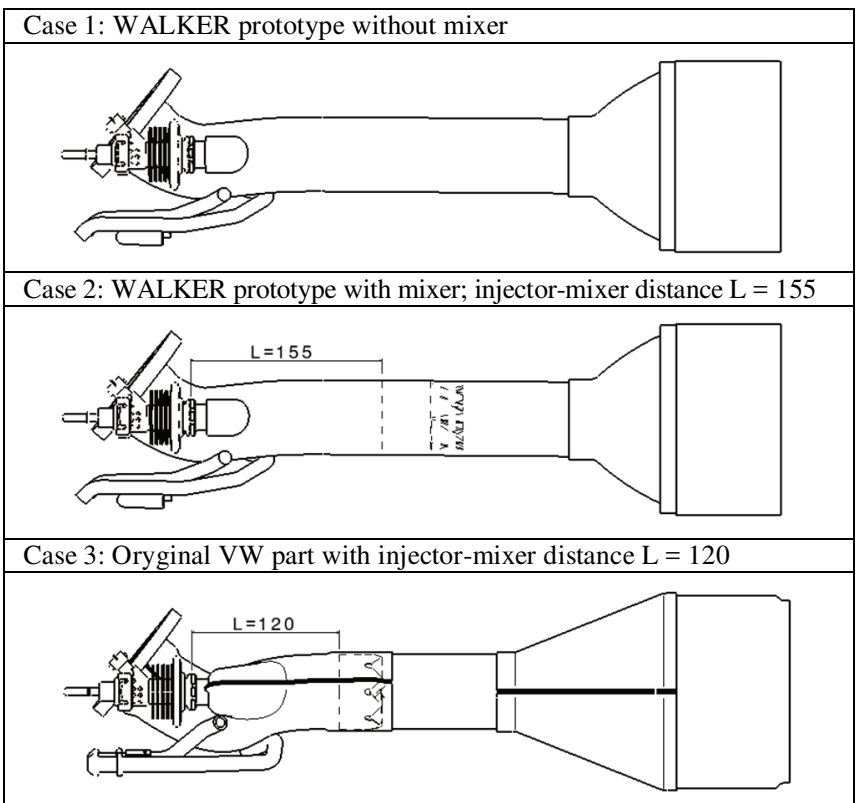


Tested static mixers (Table 3) were prepared in the Catia v5 program. Concept of WALKER mixer was planned for ease of assembly and universal operation. The mixer of VW original product was prepared on the basis of a reverse engineering, which will be discussed in the next section.

Table 3. Tested static mixers

WALKER mixer

The tested prototype had a vanadium SCR catalyst $\left(\mathrm{V}_{2} \mathrm{O}_{5}\right)$ as the active component impregnated and supported on an anatase and silica $\left(\mathrm{TiO}_{2}-\mathrm{SiO}_{2}\right)$. The tested monolith had dimensions: $5.66 \times 3$ " (diameter $\times$ length [inch]) with

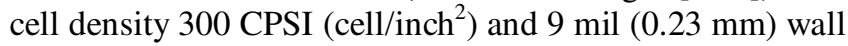
thickness.

The pressure drops in the prototype and its mixer were measured in a laboratory test facility. The test stand (Fig. 4), consisted of feed tube with mass flowmeter of air inflow (in eight growing values) and micro manometer (for static pressure) installed at the inlet side. Furthermore, the test stand allows also for measuring the temperature of air at the inlet feed tube and ambient temperature and pressure. Through the LabVIEW software, the results were collected.

The tested prototype was equipped with flanges that connected the mixer to the pipes. It was therefore possible to quickly adapt the prototype to mixer.

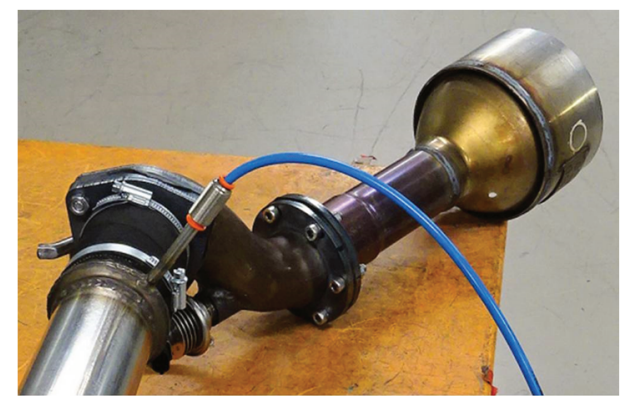

Fig. 4. Measurements of pressure drop in a laboratory test facility

For WALKER mixer, the experimental results of pressure drops were collected and used for calculating the coefficients (of viscous and inertial resistance for CFD simulations) based on the quadratic polynomial equation and compared with Darcy-Forchheimer equation, as it was presented in details in our previous study [8]. In the plot (Fig. 5) there are differences in pressure drops for tested mixer and a reference case without mixer.

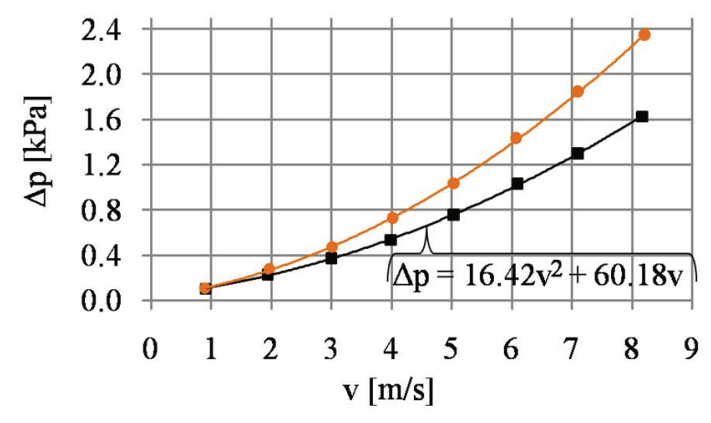

- Proto w/o mixer - Proto with mixer

Fig. 5. Pressure drop vs. velocity for WALKER prototypes

Another test stand (Fig. 6), was used to study the velocity distribution at the monolith's outlet surface. The construction of the $\mathrm{X}-\mathrm{Y}$ platform allows for automatic scanning of the entire cross-section area with a resolution of approximately 150 sampling points. The locally measured value by anemometer was recorded and the velocity profile was generated on this basis as it was in similar Tenneco Edenkoben study from Gehrlein et al. [5].

The laboratory test stand allows also to determine the NOx reduction efficiency and urea conversion under steady state condition. In order to mimic as much as possible the given operating parameter of the engine in real time, the stand has electric heaters, $\mathrm{NO}_{\mathrm{x}}$ gas dispenser, UWS dosing and sampling probe for CLD (chemo luminescence detector). I addition, it is equipped with mass flow, temperature and pressure sensors.

In this article, the conversion of $\mathrm{NO}_{\mathrm{x}}$ will be omitted, only the distribution of ammonia on the outlet surface of SCR monolith will be presented in order to compare it with CFD simulation results. Further research, however, will take into account the experimental results of $\mathrm{NO}_{\mathrm{x}}$ reduction efficiency and comparing them with numerical simulations.

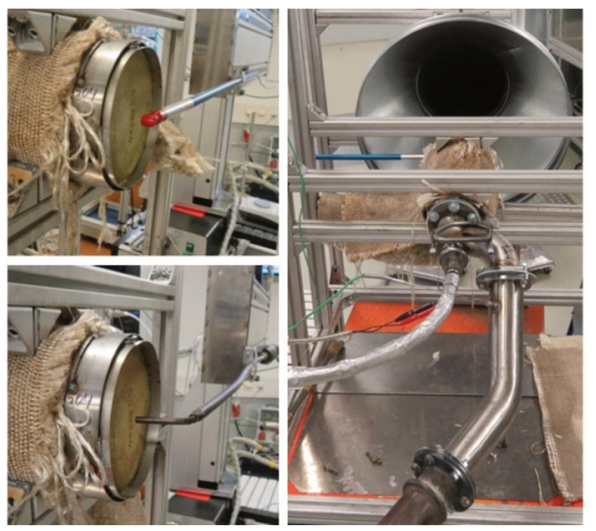

Fig. 6. Measurements of flow distribution in a laboratory test facility

\section{Reverse engineering}

To determine the correct geometry of the 3D model for CFD simulation, reverse engineering process was used. Here, the reverse engineering should be understood as the process of obtaining a geometric CAD model from 3D points by scanning or digitizing existing part [8].

In the first phase of the process, the aftermarket prototype (AM) and mixer were scanned using a laser scanner (ROMER Absolute Arm). Noncontact scanning technology 
allows to obtain a cloud of points from parts in Metrolog $\mathrm{X} 4$ software, which define the surface geometry.

The next step was loading the point cloud data (TXT format file) to the Leios 2 software. Cleaning of noise and reduction of the number of points were applied. Using built-in tools, triangle meshes and cross-sections as NURBS (Non-uniform rational B-spline) were generated.

Finally, based on the base data from Leios 2 (crosssections, points, planes), 3D models in Catia v5 were reconstructed (Fig. 7).

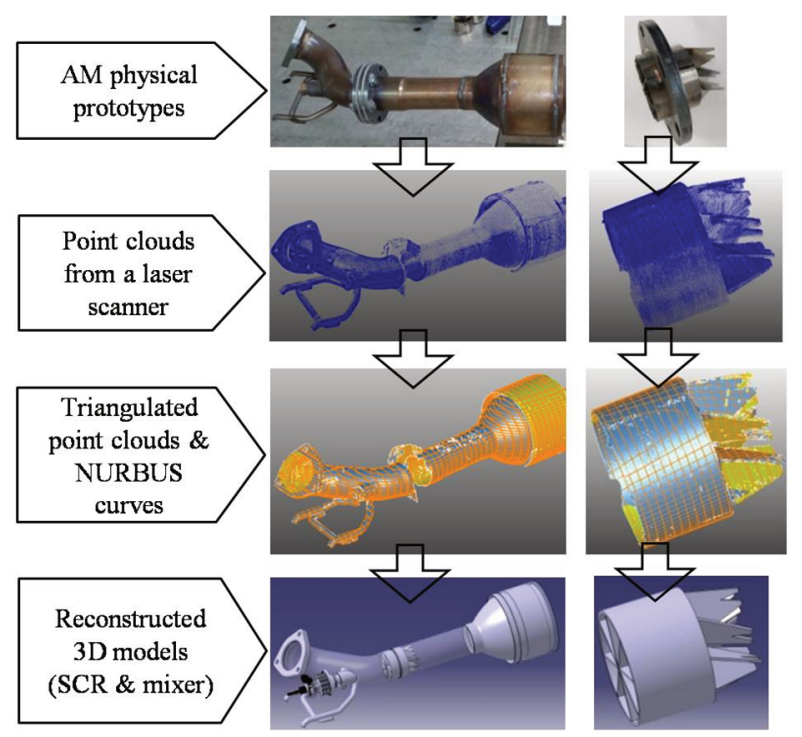

Fig. 7. Process of reverse engineering for AM prototype SCR and mixer

The reverse engineering for the original part (Fig. 8) was similar as in WALKER prototype. The exception was in VW mixer, in which the process ran differently due to not destroying parts (mixer cutout). Therefore, using the OLYMPUS IMPLEX NX videoscope, the original mixer was reviewed, and thanks to this, the 3D model of the mixer in Catia v5 program was reproduced as closely as possible.

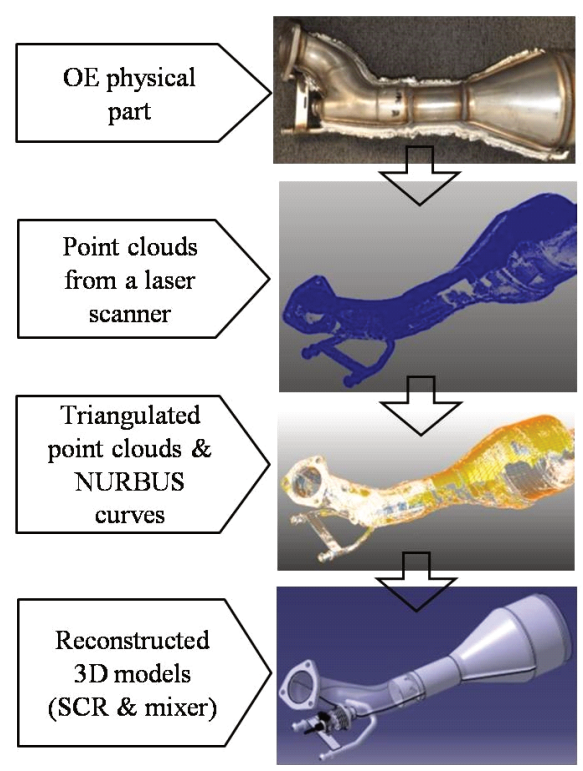

Fig. 8. Process of reverse engineering for OE SCR

\section{CFD modeling}

For CFD simulations, internal models of SCR with cut out mixer geometry had to be prepared. Models have been simplified in such a way that all the insignificant details (edges, fillets, grooves) were removed. This allowed for a better mesh adjustment (tetrahedral and hexahedral) with acceptable mesh quality (orthogonal quality, skewness etc.).

Steady state flow simulation through the SCR were performed. The governing equations for the flow within the domain are RANS (Reynolds Averaged Navier-Stokes) equations consisting of the conservation of mass, momentum and energy equation [8]. The flow inside the porous medium (monolith) was treated as laminar, whereas in the remaining volume of the flow domain the turbulence was modeled by means of the Realizable $\mathrm{k}-\varepsilon$ model.

Numerical simulation were carried out in two ways (Table 4). First, simulations were carried out only for ideal gas flow and ambient temperature ("cold flow"). This allowed for comparison of the CFD results with experimental tests (distribution of velocity fields and pressure drops).

In the second type of CFD simulation ("hot flow") also contains species transport with volumetric reactions by using laminar interactions between UWS and inflow of the mixture. In this case the DPM (Discrete Phase Model) was applied for three injections. Such settings allowed to check the degree of mixing and distribution of $\mathrm{NH}_{3}$ in monolith.

Table 4. General settings for simulations in ANSYS Fluent

\begin{tabular}{|c|c|}
\hline \multicolumn{2}{|c|}{ COLD FLOW - without UWS } \\
\hline Analysis type & Steady state with 250 iterations \\
\hline Turbulence model & к-epsilon; realizable \\
\hline Near-wall treatment & Standard wall functions \\
\hline Working fluid & Air: ideal gas \\
\hline Porous media & Laminar, porous with viscous \& inertial coef. \\
\hline Inlet conditions & Mass flow rate $115 \mathrm{~kg} / \mathrm{h} \&$ ambient temp. $295 \mathrm{~K}$ \\
\hline Outlet conditions & Open to atmosphere \& ambient temp. $295 \mathrm{~K}$ \\
\hline \multicolumn{2}{|c|}{ HOT FLOW - with UWS } \\
\hline Analysis type & Steady state with 500 iterations \\
\hline Turbulence model & к-epsilon; RNG \\
\hline Near-wall treatment & Standard wall functions \\
\hline Species transport: & Mixture of urea-water-air \\
\hline - Reactions & Laminar finite-rate interaction + diffusions \\
\hline DPM & Continuous phase \& Iteration + Latent Heat \\
\hline Injection $\mathrm{x} 3$ : & Solid-cone with multicomponent particle type \\
\hline - Material & Urea-water $\left(32.5 \% \mathrm{CO}\left(\mathrm{NH}_{2}\right) 2 ; 67.5 \% \mathrm{H}_{2} \mathrm{O}\right)$ \\
\hline - Dia. distribution & Rosin-Rammler \\
\hline - Temperature & $293 \mathrm{~K}(\mathrm{UWS})$ \\
\hline - Velocity & $20 \mathrm{~m} / \mathrm{s}$ \\
\hline - Outer radius & $60 \mu \mathrm{m}$ (radius of injector hole) \\
\hline - Cone angle & $4^{\circ}$ (included half-angle) \\
\hline - Total flow rate & $0.021 \mathrm{~kg} / \mathrm{h}$ \\
\hline - Min. diameter & $4 \mu \mathrm{m}$ (the smallest droplet diameter) \\
\hline - Max. diameter & $80 \mu \mathrm{m}$ (the largest droplet diameter) \\
\hline - Mean diameter & $50 \mu \mathrm{m}$ \\
\hline - Spread parameter & 3.5 (for a single-phase nozzle) \\
\hline - No. of diameters & 5 (no. of diameters in each distribution) \\
\hline Vaporization model & Urea-water: convection/diffusion-controlled \\
\hline Porous media & Laminar, porous with viscous \& inertial coef. \\
\hline Inlet conditions: & Mass flow rate $206 \mathrm{~kg} / \mathrm{h} \&$ temp. $677 \mathrm{~K}$ \\
\hline - Species mass frac. & $6.1 \% \mathrm{O}_{2} ; 7 \% \mathrm{H}_{2} \mathrm{O} ; 14.6 \% \mathrm{CO}_{2}$ \\
\hline Outlet conditions & Open to atm. (pressure outlet) \& temp. $677 \mathrm{~K}$ \\
\hline Walls: DPM & Boundary cond. type: reflect \\
\hline
\end{tabular}

The whole process of preparing a simulation model for the WALKER prototype and the original VW part, is briefly presented in Fig. 9 and Fig. 10. 


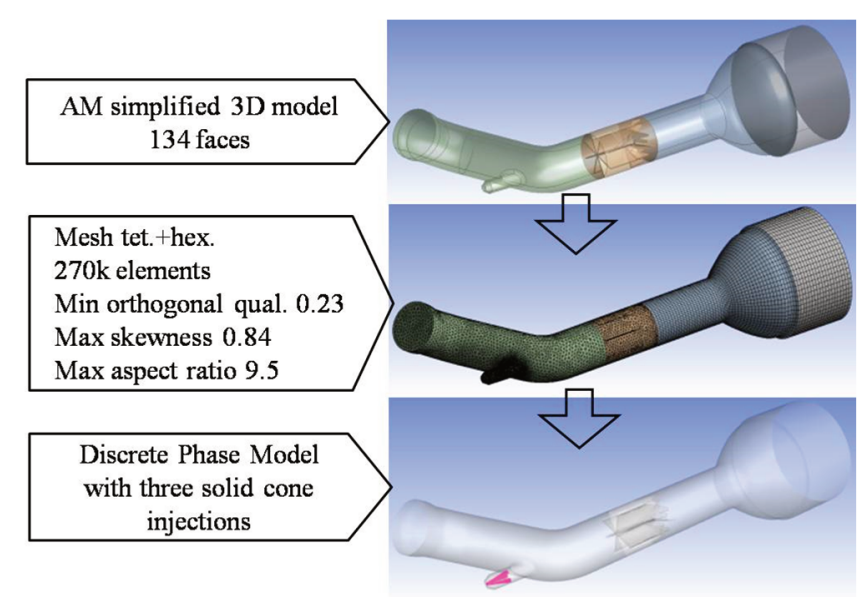

Fig. 9. Process of preparation of AM 3D model for CFD simulation

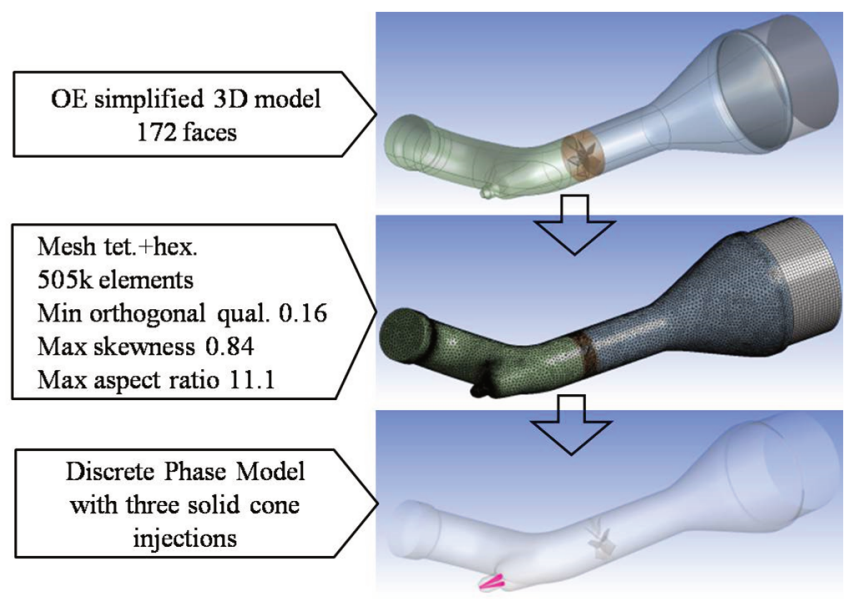

Fig. 10. Process of preparation of OE 3D model for CFD simulation

In ANSYS Fluent, the Rosin-Rammler distribution function is used to initialize droplets size distribution into the gas phase. The mass fraction $\mathrm{Y}_{\mathrm{d}}$ of droplets of diameter greater than $\mathrm{d}$ can be given by [13]:

$$
Y_{d}=e^{-(d / \bar{d})^{n}}
$$

where: $\mathrm{d}$ - diameter, $\overline{\mathrm{d}}$ - size constant (mean diameter), $\mathrm{n}$ - size distribution parameter (spread parameter).

The effect of the convective flow of the evaporating material from the droplet surface to the bulk gas phase (Stefan Flow) and the rate of evaporating mass (convection/diffusion controlled model) is given by [13]:

$$
\frac{\mathrm{dm}_{\mathrm{p}}}{\mathrm{dt}}=\mathrm{k}_{\mathrm{c}} \mathrm{A}_{\mathrm{p}} \rho \ln \left(1+\mathrm{B}_{\mathrm{m}}\right)
$$

where: $\mathrm{m}_{\mathrm{p}}-$ droplet mass, $\mathrm{k}_{\mathrm{c}}-$ mass transfer coefficient, $A_{p}$ - droplet surface area, $\rho$ - gas density, $B_{m}-$ is the Spalding mass number given by:

$$
B_{m}=\frac{Y_{i, s}-Y_{i, \infty}}{1-Y_{i, s}}
$$

where: $Y_{i, s}$ - vapor mass fraction at the surface, $Y_{i, \infty}$ - vapor mass fraction in the bulk gas.

The mass transfer coefficient $\mathrm{k}_{\mathrm{c}}$ is calculated from the Sherwood number correlation [13]:

$$
\mathrm{Sh}=\frac{\mathrm{k}_{\mathrm{c}} \mathrm{d}_{\mathrm{p}}}{\mathrm{D}_{\mathrm{i}, \mathrm{m}}}=2.0+0.6 \mathrm{Re}_{\mathrm{d}}^{1 / 2} \mathrm{Sc}^{1 / 3}
$$

where: $d_{p}-$ droplet diameter, $D_{i, m}-$ diffusion coefficient of vapor in the bulk, $\mathrm{Re}_{\mathrm{d}}-$ Reynolds no., Sc - Schmidt no.

\section{Results}

Selected cases will be presented and compared with experimental and numerical results. Furthermore, the main flow parameters in the SCR system will be discussed.

To evaluate the velocity flow distribution, the uniformity index is commonly used. The uniformity index (UI) represents how a specified field variable varies over a surface, where a value of 1 indicates the highest uniformity. The area-weighted (captures the variation of the quantity) of UI is calculated using the following equation [13]:

$$
\gamma=1-\frac{\sum_{\mathrm{i}=1}^{\mathrm{n}}\left[\left(\left|\phi_{\mathrm{i}}-\bar{\emptyset}\right|\right) \mathrm{A}_{\mathrm{i}}\right]}{2|\bar{\emptyset}| \sum_{\mathrm{i}=1}^{\mathrm{n}} \mathrm{A}_{\mathrm{i}}}
$$

where: $\varnothing$ - specified field variable, $\bar{\emptyset}$ - average value of the field variable, $\mathrm{n}$ - number of facets, $\mathrm{i}$ - facet index of a surface, $\mathrm{A}$ - surface area.

Uniformity index $\gamma \geq 0.94$ can be treated as a very good result and the value at this level is considered satisfactory.

Comparing the results (Fig. 11) of CFD and experiments, it can be concluded that the pictures of the velocity fields look similar. In the final results for that case (Table 5), UI for CFD is 0.961 while for experiment it is 0.952 .

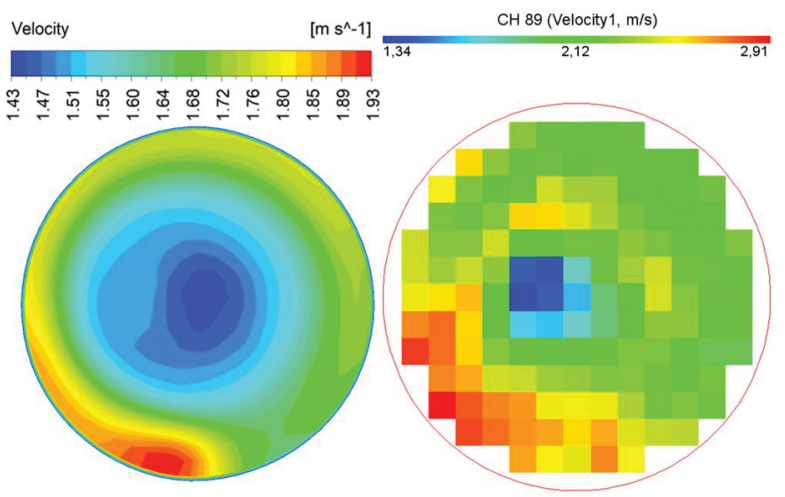

Fig. 11. Case 2: CFD vs. experimental (velocity distribution on the outlet)

Figure 12 shows sampling from the monolith outlet surface through zigzag movement from bottom to top.

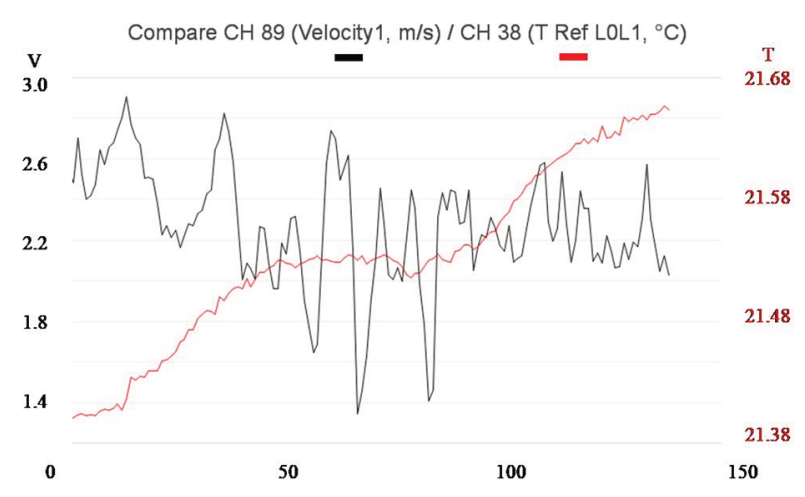

Fig. 12. Case 2: velocity and temperature distribution on the outlet 
The next parameter for checking the flow in the SCR system is ETA index. ETA $10 \%$ should be $>0.7$ whereas for ETA $20 \%$ value 1.0 is required. And for example, ETA $10 \%$ is area range with velocity $\pm 10 \%$ of mean velocity, i.e. narrow range of areas ought to be avoided where there are large higher velocity compared to the mean velocity. However, ETA $15 \%$ (Fig. 13) has been checked for physically tested parts. For numerical simulations, ETA 15\% limit has been implemented into ANSYS Fluent using User Defined Functions (UDFs) through Microsoft Visual Studio 2017 and $\mathrm{C}++$ language.

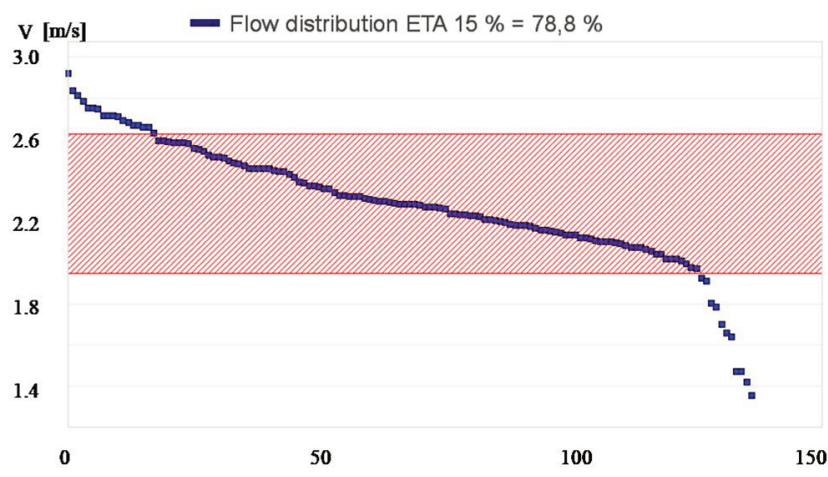

Fig. 13. Case 2: flow distribution (velocity) on the outlet (ETA 15\%)

In turn, the Eccentricity index (7) determines the place on the monolith surface with the highest flow rate. It is desirable that such sites do not occur at the edge of the monolith, therefore this parameter should be $\leq 0.5$. Eccentricity is specified by the following equation:

$$
\text { Eccen. }=\frac{r_{v_{\text {max }}}}{R}
$$

where: $r_{\mathrm{v}_{\max }}-$ radius to the point of maximum velocity, $\mathrm{R}$ - radius to the edge of monolith.

The velocity streamlines in the SCR system (Fig. 14), illustrate the direction of gas mixing. In CFD, to determine pressure drops within the mixers, inlet and outlet facet average of static pressure (difference) calculated.
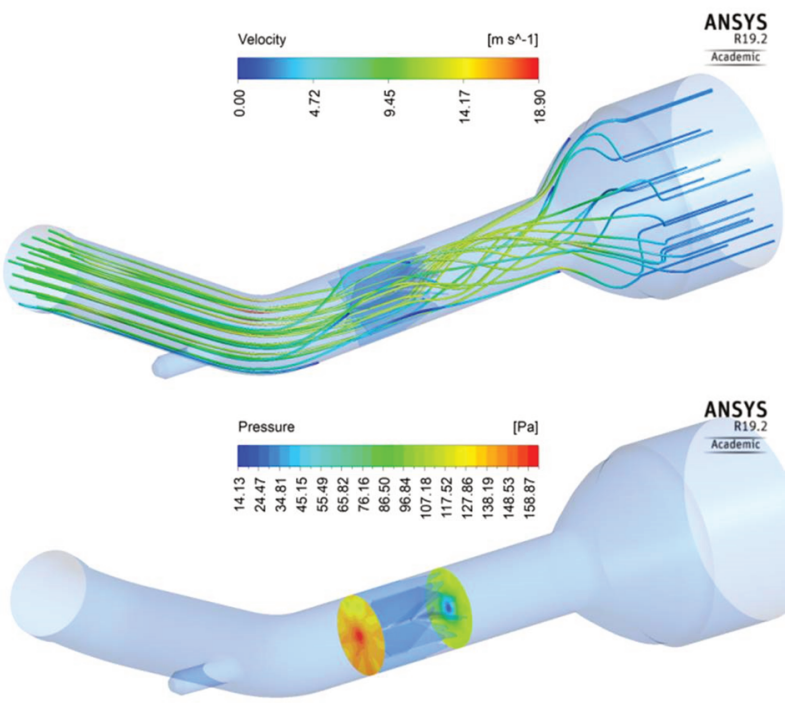

Fig. 14. Case 2: velocity flow and pressure drop through mixer
The pressures in the entire SCR system (Fig. 15) have been compared through volume rendering. The exhaust gas pressure drops over the whole exhaust system is equal to exhaust pressure at the manifold (backpressure). Excessive backpressure creates overmuch heat, lowers engine power, fuel consumption and damage of the engine parts. Therefore, backpressure in a certain level leads to improvement of the engine performance and reduces emissions [8].

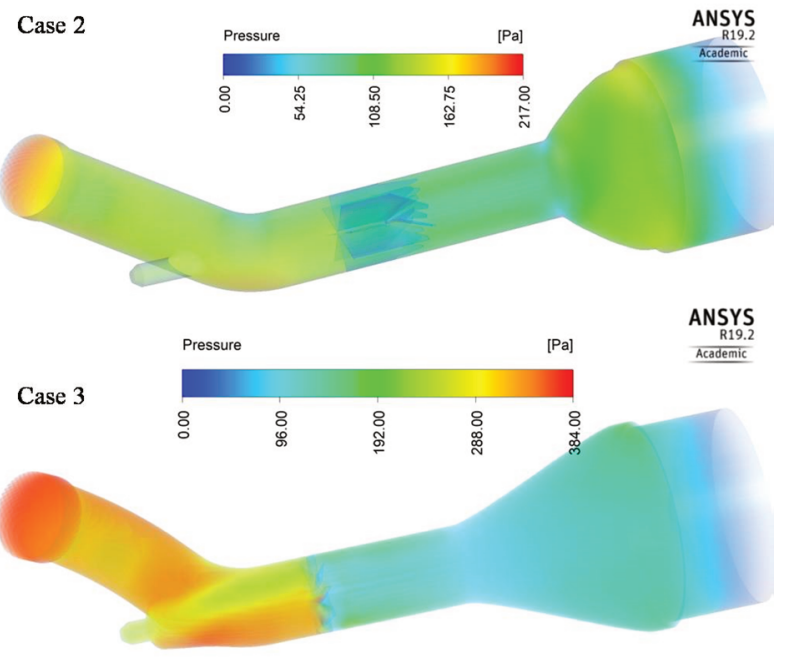

Fig. 15. Static pressure for the whole SCR

Subsequent simulations were carried out with an injection of UWS (Fig. 16). In this view, the case 2 has a greater use of the mixer at the bottom while for the VW part shows mostly distribution of UWS on the edges of the walls.

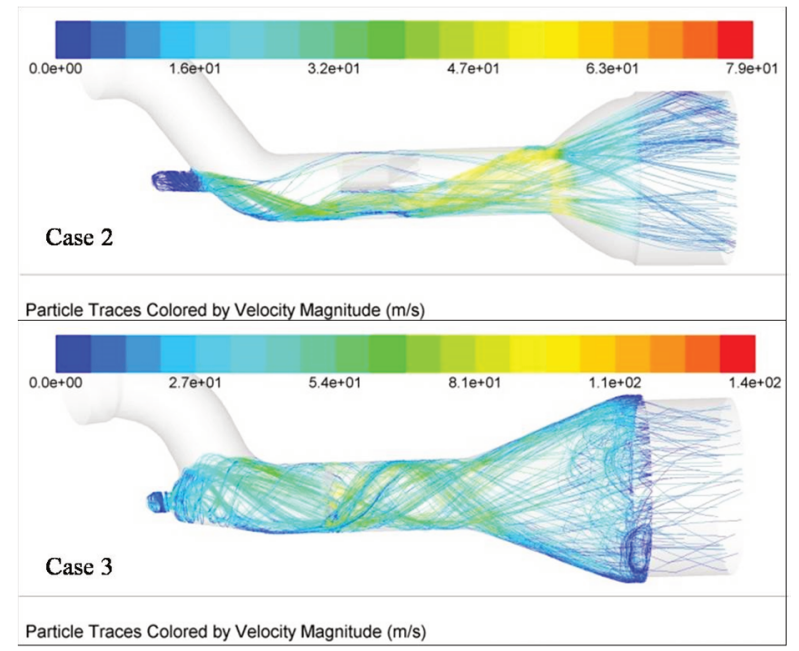

Fig. 16. Velocity particle trajectories of UWS through mixer

Mixture homogeneity is one of the most important parameters used in SCR systems. To evaluate the quality of mixing degree of ammonia with exhaust gases, the coefficient of variation $(\mathrm{CoV})$ is used and defined as [14]:

$$
\operatorname{CoV}=\frac{\sigma}{\overline{\mathrm{x}}}=\frac{1}{\overline{\mathrm{x}}} \sqrt{\frac{\sum_{\mathrm{i}=1}^{\mathrm{n}}\left(\mathrm{x}_{\mathrm{i}}-\overline{\mathrm{x}}\right)^{2}}{\mathrm{n}}}
$$

where: $\sigma$-standard deviation, $\mathrm{x}_{\mathrm{i}}$ - each of the values of the data, $\bar{x}-$ the mean of the $x_{i}, n-$ the number of data points. 
$\mathrm{CoV}$ is defined as the standard deviation of concentration (e.g. $\mathrm{NH}_{3}$ ), over the mean concentration. If the value of $\mathrm{CoV}$ is equal to zero, it means that system is mixed completely and the efficiency of mixing operation is $100 \%$. A large $\mathrm{CoV}$ means an uneven distribution of ammonia.

For previously presented cases (Fig. 16), the mixing of ammonia (mole fraction of $\mathrm{NH}_{3}$ ) on the front surface of the monolith (Fig. 17) was also compared. At this point, mixing degree should be the best due to starting the chemical reactions with the SCR catalyst. In this case it turned out to be better WALKER mixer $\left(\mathrm{NH}_{3} \mathrm{CoV}=0.60\right.$ and $\left.\mathrm{UI}=0.755\right)$.
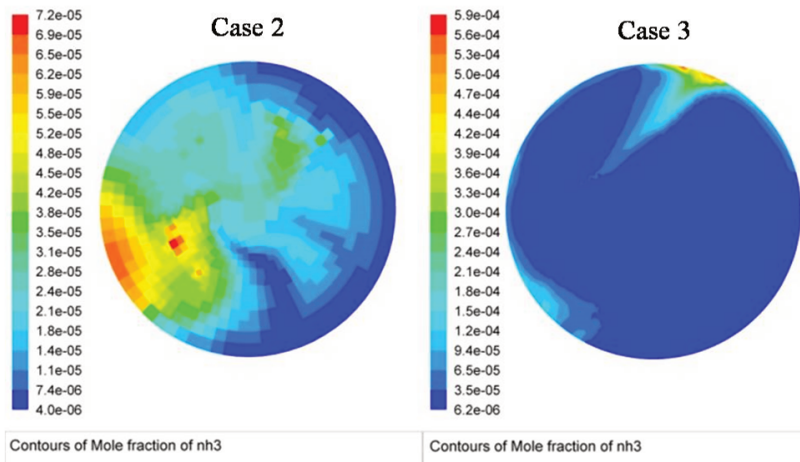

Fig. 17. Mole fraction of $\mathrm{NH}_{3}$ on the inlet face of monolith

The undesirable phenomenon of "ammonia slip" on the monolith's outlet surface has also been compared (Fig. 18).

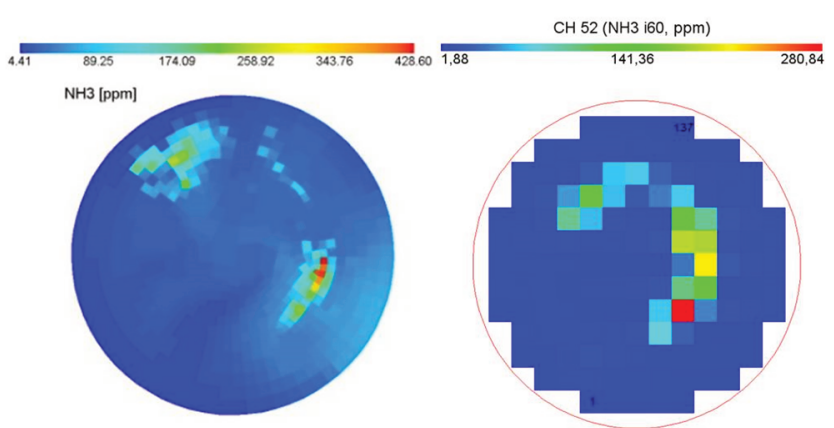

Fig. 18. Case 2: CFD vs. experimental $\left(\mathrm{NH}_{3}\right.$ on the outlet face)

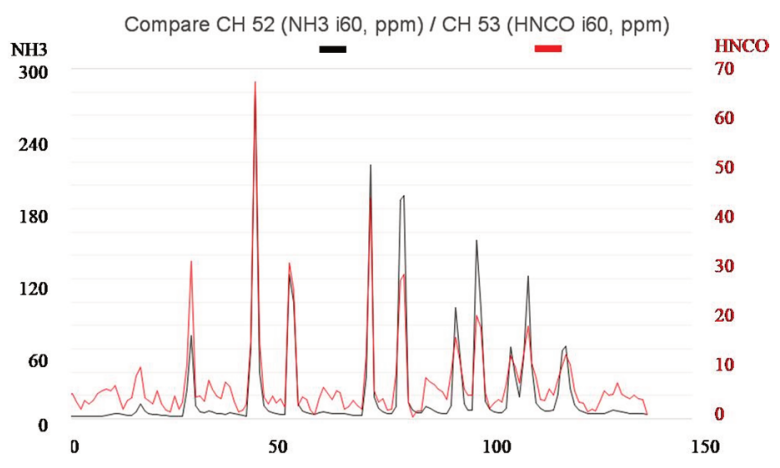

Fig. 19. Case 2: $\mathrm{NH}_{3}$ vs. HNCO on the outlet face

The mole fraction of $\mathrm{NH}_{3}$ were higher compared to the experimental results due to not taking into account the $\mathrm{NO}_{\mathrm{x}}$ reactions. The presence of a large amount of $\mathrm{NH}_{3}$ also causes presence of isocyanic acid (Fig. 19) which can lead to undesirable deposit.
The remaining results and their comparisons are presented in the final table (Table 5).

Table 5. Experimental and numerical results for the studied cases

\begin{tabular}{|c|c|c|c|}
\hline \multirow{2}{*}{ Unit } & w/o mixer & WALKER mixer & OE VW mixer \\
\hline & Case 1 & Case 2 & Case 3 \\
\hline UI v. e. & N/A & 0.952 & N/A \\
\hline UI v. n. & 0.963 & 0.961 & 0.961 \\
\hline BP e., mbar & 2.11 & 2.43 & N/A \\
\hline BP n., mbar & 1.92 & 2.17 & 3.84 \\
\hline$\Delta \mathrm{P}$ e., $P a$ & $\mathrm{w} / \mathrm{o}$ & 32 & N/A \\
\hline$\Delta \mathrm{P}$ n., $P a$ & $\mathrm{w} / \mathrm{o}$ & 34 & 211 \\
\hline ETA $15 \%$ e. & N/A & 78.8 & N/A \\
\hline ETA $15 \% \mathrm{n}$. & 90.0 & 95.0 & 88.6 \\
\hline Eccen. e. & N/A & 0.89 & N/A \\
\hline Eccen. n. & 0.19 & 0.47 & 0.46 \\
\hline $\mathrm{CoV} \mathrm{NH} 3$ & 1.11 & 0.60 & 1.87 \\
\hline $\mathrm{UI} \mathrm{NH}_{3}$ & 0.552 & 0.750 & 0.647 \\
\hline \multicolumn{4}{|c|}{$\begin{array}{l}\text { e. - experimental results; } \mathrm{n} \text {. - numerical results (CFD); v. - velocity; } \\
\text { UI v. - uniformity index of velocity on the outlet surface of monolith; } \\
\text { BP - max. static pressure in SCR; } \triangle \mathrm{P} \text { - pressure drop of the mixer; } \\
\text { ETA15\% - index of velocity on the outlet surface of monolith; } \\
\text { Eccen. - Eccentricity of velocity on the outlet surface of monolith; } \\
\text { CoV NH3 - coef. of variation for } \mathrm{NH}_{3} \text { on the inlet surface of monolith; } \\
\text { UI NH3 - uniformity index for } \mathrm{NH}_{3} \text { on the inlet surface of monolith; } \\
\text { N/A - result not available (experimental study not carried out). }\end{array}$} \\
\hline
\end{tabular}

\section{Summary}

The SCR system without mixer has smallest pressure drop, however, along with the complexity of the mixer construction, the pressure drop in the system increases but at the expense of this the uniformity index of $\mathrm{NH}_{3}$ and degree of $\mathrm{NH}_{3}$ mixing $(\mathrm{CoV})$ are improved.

Although the WALKER and the original VW mixer had the same UI for velocity gas distribution, the WALKER mixer had better level of mixing $(\mathrm{CoV})$ and $\mathrm{UI}$ of $\mathrm{NH}_{3}$ distribution. Surprisingly, the mixer of the original part had poor level of mixing $\left(\mathrm{NH}_{3}\right.$ with highest concentration on the walls) and large pressure drop on the mixer.

High level of ammonia slip in the results, can be explained by the fact that the tests were performed only with the participation of the first SCR reactor, while the original part has two separate SCR reactors connected by a intermediate tube, thanks to which ammonia slip can be eliminated and the level of mixing even better. Simulations confirm this, because about half of UWS have evaporated, while it should be completely evaporated before reaching the monolith. This could also be achieving by reducing the gas flow rate, use a longer pipe or inlet cone for better mixing or using additional thermal insulation for SCR.

The position and rotation angle of the mixer in the SCR is important. When the droplets of UWS do not hit the mixer and just pass and hit the wall, there may be a risk of creating a deposit. Therefore, various attempts to set up the mixer should be used, so that the concentration of $\mathrm{NH}_{3}$ was symmetrical after mixer and until reaching the monolith.

Small differences in the results between CFD simulations and experimental studies can be explained by the fact that the 3D models for numerical simulations have been simplified and thus the flow inside the SCR system is less disturbed than in the physical parts. Furthermore, the measurement uncertainties contribute to the differences as well.

The test results did not reach a very high level. Improvements regarding the construction of a static mixer and $\mathrm{NO}_{\mathrm{x}}$ conversion studies will be the subject of further work. 
Acknowledgements

D.K. acknowledges support from the Tenneco company. This work was partly supported by the Faculty of Power and Environmental Engineering of the Silesian University of Technology within the statutory research fund.

\section{Nomenclature}

CF Conformity Factor

CFD Computational Fluid Dynamic

CLD Chemo Luminescence Detector

CoV Coefficient of Variation

DEF Diesel Exhaust Fluid

DPF Diesel Particulate Filter

DPM Discrete Phase Model

LNT Lean NOx Traps

NEDC New European Driving Cycle

NSC NOx Storage Catalyst
NURBS Non-Uniform Rational B-Spline

PEMS Portable Emission Measurement System

PM Particulate Matter

PN Particulate Number

RDE Real Driving Emission

SCR Selective Catalytic Reduction

SDPF SCR-Catalyzed Diesel Particulate Filter

UI Uniformity Index

UWS Urea-Water Solution

WLTP World Harmonised Light Vehicle Test Procedure

\section{Bibliography}

[1] BALOGH, R.M., IONEL, I., STEPAN, D. et al. $\mathrm{NO}_{\mathrm{x}}$ reduction using selective catalytic reduction system- $\alpha$ variation test. Termotehnica. 2011, 38-42.

[2] BRZEŻAŃSKI, M. Diesel engines with respect to Euro 6 and BIN5/LEV II emission limits. Journal of KONES Powertain and Transport. 2011, 18(4), 33-40.

[3] BRZEŻAŃSKI, M., SALA, R. In-service problems of selective catalytic reduction systems for reduction of nitrogen oxides. Comb. Eng. 2013, 154(3), 969-976.

[4] FLOYD, R., MICHAEL, L., SHAIKH, Z. DEF systems and aftertreatment architecture considerations. In Urea-SCR Technology for deNOx After Treatment of Diesel Exhaust, edited by NOVA, I., TRONCONI, E. Springer, 2014, 455483. DOI: $10.1007 / 978-1-4899-8071-7 \_15$

[5] GEHRLEIN, J., LANG A., PALEMR G. Optimierung von SCR-Systemen durch Integration von Mischelment. Motortech. Z., 2009, 70, 218-223.

[6] HOOFMAN, N., MESSAGIE, M., VAN MIERLO, J. et al. A review of the European passenger car regulations - real driving emissions vs local air qua-lity. Renewable and Sustainable Energy Reviews. 2018, 86, 1-21. DOI: 10.1016/ j.rser.2018.01.012

[7] KRÖCHER, O. Chapter 9. Aspects of catalyst development for mobile urea-SCR systems - from vanadia-titania catalysts to metal-exchanged zeolites. Studies in Surface Science and Catalysis. 2007, 171, 261-289. DOI: 10.1016/ S0167-2991(07)80210-2

[8] KURZYDYM, D., KLIMANEK, A., ŻMUDKA, Z. Experimental and numerical analysis of flow through catalytic converters for original part and WALKER's replacement using reverse engineering and CFD. Int. Automotive Conf.
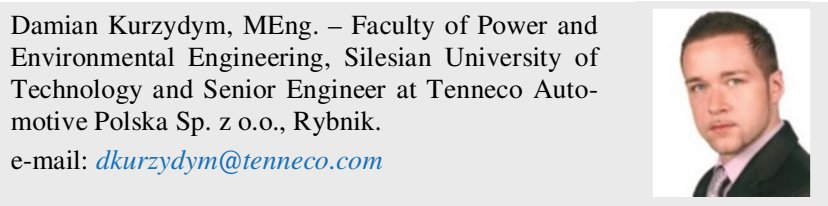

Zbigniew Żmudka, DSc., DEng. - Faculty of Power and Environmental Engineering, Silesian University of Technology, Gliwice, Poland.

e-mail: zbigniew.zmudka@polsl.pl
(KONMOT 2018), IOP Conf. Series: Mat. Sci. and Eng. 2018, 421. DOI: 10.1088/1757-899X/421/4/042044

[9] LAUER, T. Preparation of ammonia from liquid AdBlue modeling approaches and future challenges. Chemie Ingenieur Technik. 2018, 90(6), 783-794. DOI: 10.1002/cite. 201700107

[10] MERKISZ, J., PIELECHA, J. Selected remarks about RDE test. Combustion Engines. 2016, 166(3), 54-61. DOI: 10.19206/CE-2016-340

[11] SALA, R., KRASOWSKI, J., DZIDA, J., WOODBURN, J. Experimental of selective catalytic reduction retrofit for Euro $6 \mathrm{NO}_{\mathrm{x}}$ emission level compliance for euro 5 light duty vehicle. Int. Automotive Conf. (KONMOT 2018), IOP Conf. Series: Mat. Sci. and Eng. 2018, 421. DOI: 10.1088/1757899X/421/4/042070

[12] SHAHARIAR, G.H., LIM, O.T. A study on urea-water solution spray-wall impingement process and solid deposit formation in urea-SCR de-NOx system. Energies. 2019, 12(1). DOI: 10.3390/en12010125

[13] TAN, L., FENG, P., YANG,S. et al. CFD studies on effects of SCR mixers on the performance of urea conversion and mixing of the reducing agent. Chem. Eng. \& Process: Process Intensification. 2018, 123, 82-88. DOI: 10.1016/ j.cep.2017.11.003

[14] TIAN, X., XIAO, Y., ZHOU, P. et al. Study on the mixing performance of static mixers in selective catalytic reduction (SCR) systems. Journal of Marine Eng. \& Technology. 2015, 14(2), 57-60. DOI: 10.1080/20464177.2015.1096615

[15] ZHENG, G., PALMER, G., SALANTA, G., KOTRBA, A. Mixer development for urea SCR applications. SAE Technical Paper. 2009. DOI: 10.4271/2009-01-2879

Adam Klimanek, DSc., DEng. - Faculty of Power and Environmental Engineering, Silesian University of Technology, Gliwice, Poland.

e-mail: adam.klimanek@polsl.pl

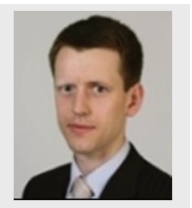

